\title{
Developing Web-Based Project Management Application for Event Organizer ABC
}

\author{
Bintoro Adi Guna \\ Informatics Engineering \\ Petra Christian University \\ Surabaya, Indonesia
}

\author{
Alexander Setiawan \\ Informatics Engineering \\ Petra Christian University \\ Surabaya, Indonesia
}

\author{
Rudy Adipranata \\ Informatics Engineering \\ Petra Christian University \\ Surabaya, Indonesia
}

\begin{abstract}
A B C$ is an event organizer company based in Surabaya, Indonesia. Organizing events calls for project management. Unfortunately, $A B C$ still does most of their business activities manually, which is prone to errors and mistakes such as miscalculations, loss of documents, and misinformation. To clear the vulnerability, ABC attempts to develop an application which fulfills their project management needs. The result of this research is a web-based application which is able to take and receive projects offers, assign staffs into groups, communicate with other staffs, create tasks, generate gantt tasks, create and realize project budgets, and sharing project documents.
\end{abstract}

Keywords: Event Organizer, Project, Project Management, Codelgniter, Application

\section{INTRODUCTION}

$\mathrm{ABC}$ is a company based in Surabaya which has a division in entertainment and artist management industry. In addition to offering artists for entertainment purposes, $\mathrm{ABC}$ also takes offers from clients to organize events, which calls for project management. Unfortunately, most of ABC's project management activities are still done manually and are vulnerable to various mistakes and human errors such as loss of documents, miscalculations in project cost, and misinformation between project staffs.

Such vulnerabilities urged $\mathrm{ABC}$ to develop a project management application to fulfill their needs. Therefore, the author attempted to develop an integrated and user-friendly project management application containing essential features of project management required by $\mathrm{ABC}$.

\section{BASIC THEORY}

\subsection{Project Management}

Kemp (2006) defines project as a dream with a deadline and a problem scheduled for solution [1]. Kemp (2006) also cited management in business as control [1]. If there is something uncontrolled, then there is no management in that business. From the preceding definitions, it can be concluded that project management is an act to ensure that the process of finding solution to a problem is kept under control. The term 'control' here means finished and punctual.

Project management components used in this application are as follows: scope management, time management, human resource management, cost management, and communications management.

\subsection{MySQL}

This application processes data inputted and outputted to and from MySQL databases. MySQL (My Structured Query Language) is a popular free and open-source database application. MySQL uses SQL scripting language which is a programming language adopted from English language and used to manipulate databases [3].

\subsection{PHP}

This application uses PHP for its server-side code in addition to HTML and CSS for the interface. PHP language is combined with CodeIgniter PHP framework to make development easier and faster.

PHP is an open-source programming language focused on server-side scripting, in which the codes are sent to server and executed there. Outputs from the codes are returned in the form of HTML to the client [2]. Because the codes are executed in the server, clients are not able to access the codes directly.

\subsection{Model-View-Controller Architecture}

As what has been discussed in point 2.3, CodeIgniter uses Model-View-Control (commonly referred to as MVC) architecture. The architecture splits applications into three objects: model for storing data in databases, view for the part of the application which is presented to the user, and controller which is the bridge between view and model. Controllers process input and output data given to or asked by users then place it in views for outputs or save it in models [4][5]. Figure 1 shows the MVC architecture.

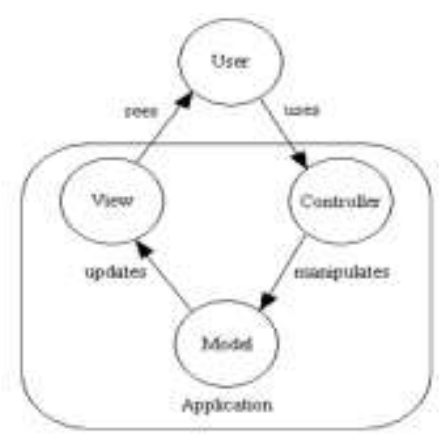

Figure 1 - MVC architecture 


\section{SYSTEM DESIGN}

\subsection{Analysis of Existing Project Management System}

Current project management system is done manually. This means that clients need to physically contact the company, either via phone, email, or coming directly to the office. After there's an agreement in scope and price, the company proceeds to assigning staffs to work on the project and creating a budget plan for the project. Company staffs assigned to work on the project would need to communicate by themselves, arrange their own schedules and tasks, and sharing documents on different locations. This keeps being done until the project is executed and completed.

\subsection{Problem Analysis of Existing Project Management System}

Current project management system is cluttered and timeconsuming especially for staffs when preparing for the project they are working on. They communicate by themselves, they schedule their own tasks, and they keep their documents online on different locations. This may lead to loss of documents, misinformation, and miscommunication between project staffs which may lead to the failure of a project. Project budgets being done manually may also lead to miscalculations and errors.

\subsection{Requirement Analysis of Existing Project Management System}

In order to combat the risks and vulnerabilities pointed out in point 3.2, it can be identified that $\mathrm{ABC}$ needs an integrated project management application which is able to facilitate staff management, communications, and schedules. Additionally, $\mathrm{ABC}$ also requires the application to be able to facilitate budgeting process, from creating budgets to realizing them.

\subsection{Data Flow Diagram (DFD)}

Data flow diagram (or DFD in short) is a graphic modelling technique showing the flow of data from external entities into the system, showed how the data moved from one process to another, as well as its logical storage [6].

\subsubsection{Context Diagram}

Context diagrams in DFD shows the overall information and entity in an application. There are five entities involved in the application: artist, administrator, user, accountant, and staff.

\subsubsection{DFD Level 0}

DFD Level 0 shows a more detailed process coming from the preceding context diagram. The name of the process involved in this application is Event Organizer Module.

\subsubsection{DFD Level 1}

DFD Level 1 shows an even more detailed process coming from the preceding DFD Level 0 . This level consists of three specific processes:

- Project registration, the act of registering projects based on requests from clients

- Project budgeting and resource allocation, the act of allocating staffs (resources) and budgets. Additionally, this process also handles budget management.

- Interstaff communication, the act of allowing staffs to communicate and give tasks with each other.

Figure 2 shows the DFD Level 1 used to develop this application.

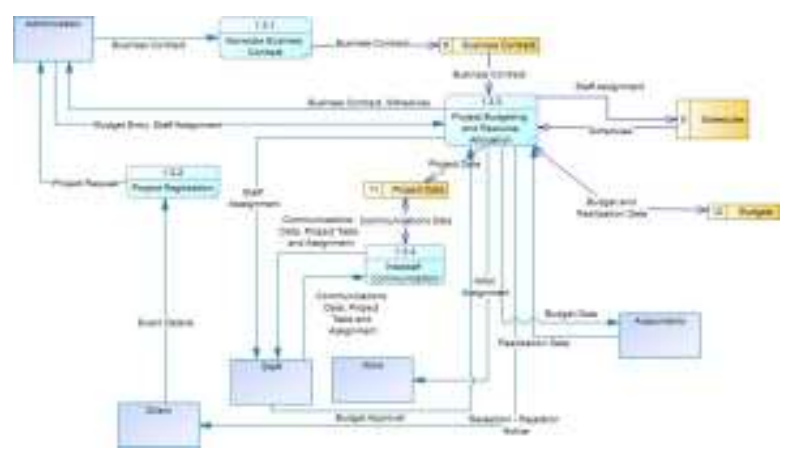

Figure 2 - DFD Level 1 of the application

\subsection{Entity Relationship Diagram (ERD)}

Entity Relationship Diagram (or ERD in short) is a modelling technique which illustrates various entities in an information system as well as their relations to each other. The term 'entity' refers to physical items or existent concepts such as users, projects, et cetera. ERD can be considered as a foundation to build an application's database. The conceptual data model for the application can be seen in Figure 3. 


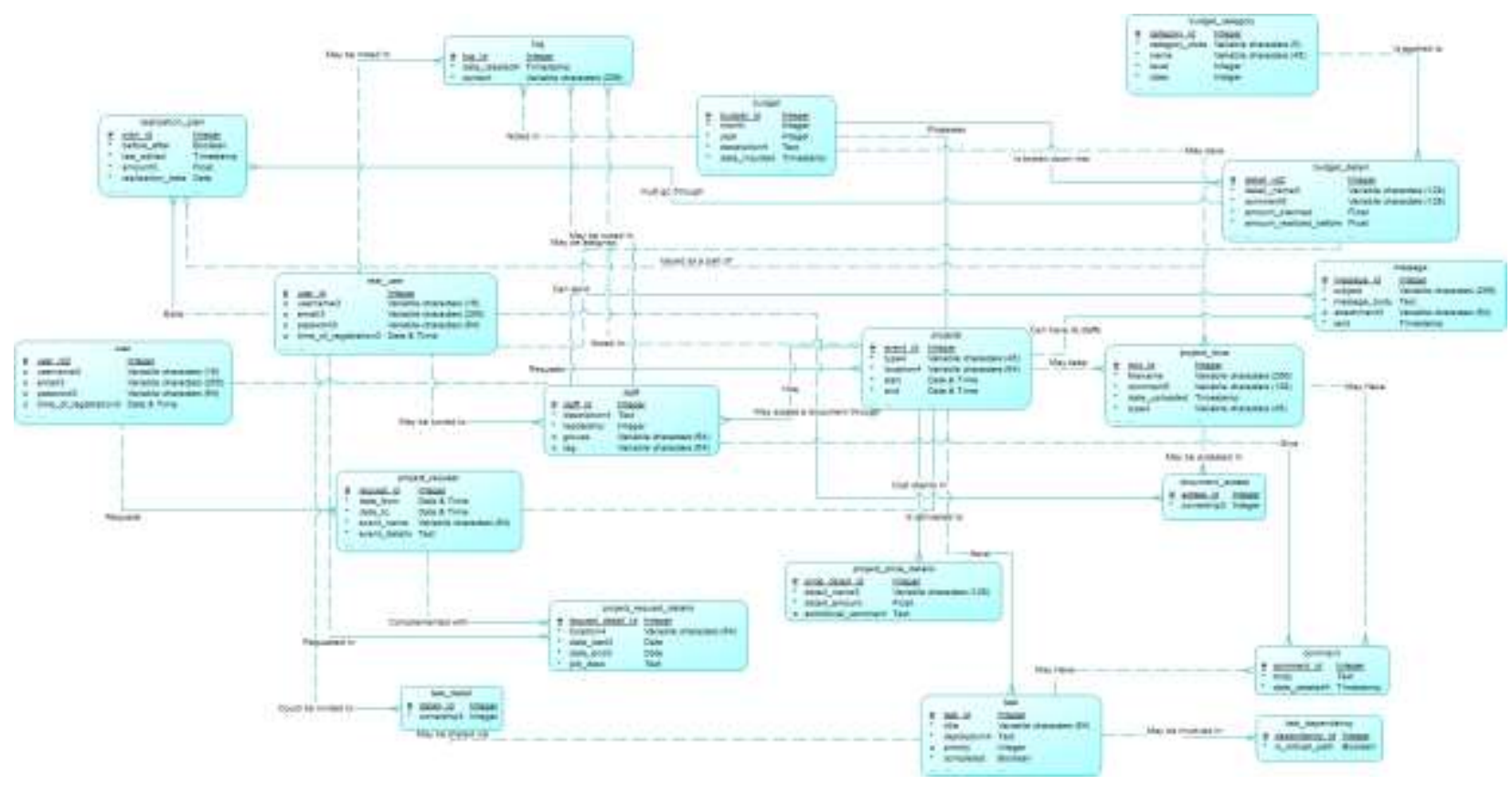

Figure 3 - Conceptual Data Model of the application

\section{APPLICATION IMPLEMENTATION}

In this chapter the author is going to explain and discuss about the developed application. This chapter is divided into subchapter in which each is going to feature a short explanation and a screenshot of the feature.

\subsubsection{Sending Project Request}

In order for a project to be recognized by the application, clients need to post their project requests by accessing the application's homepage. Clients need to register for a free account before being able to post a request. Once registered and verified, clients need to head to a section called "Client Area" then press "Request A Project" button. Clients will then be taken through a form wizard to fill the details of their desired event. The form wizard is featured in Figure 4.

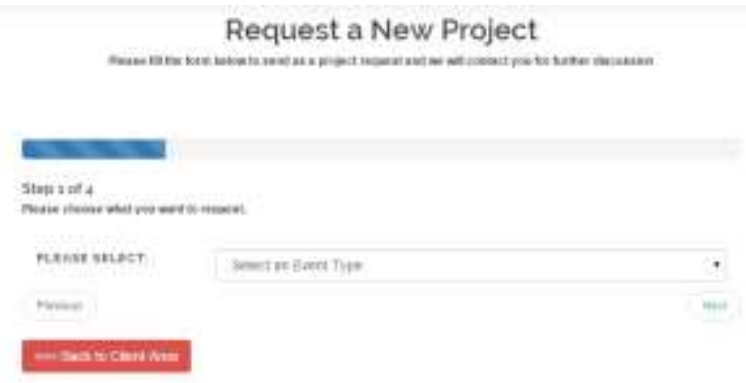

Figure 4 - Project request form wizard

\subsubsection{Responding to Project Requests}

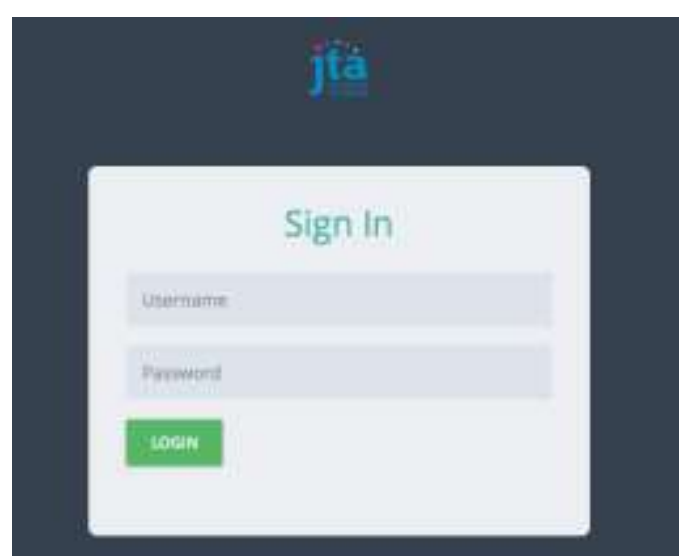

Figure 5 - Administration section log in page

Only users with admin privileges are allowed to see the project requests sent by client. Users will need to log in from the administration/back-end section of the application as seen in Figure 5. The privileged user will then be able to view and respond to project requests. Similar to clients requesting a new project, the user will also be guided via form wizard to respond the client's request. The user will be allowed to directly reject the request, or put it on hold for later. The user will need to input essential data such as project price, performers, and documents (if available). The client will be notified via email about the development of his/her project request. Figure 6 features the form wizard that guides administrators in responding to a client's project request. 


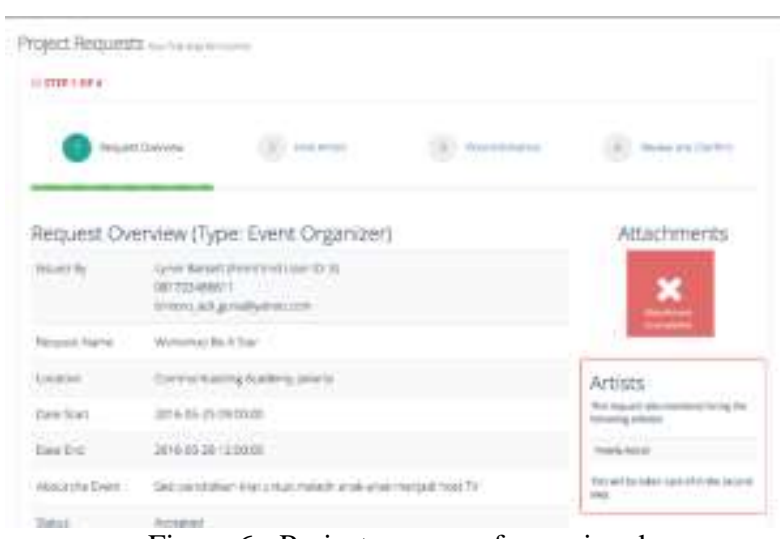

Figure 6 - Project response form wizard

Accepted project requests will be converted automatically to projects, allowing the administrators to assign staffs and create budgets for the corresponding project.

\subsubsection{Adding Resources and Budget}

After approving a project request, administrators can immediately assign staffs and create budget for the newlycreated project. Figure 7 shows the project information page which contains essential information such as project name, location, status, value, staffs, and link to budget.

Administrators can also assign staffs from this page.

Administrators can either register new staffs or select existing ones. Not only adding staffs, administrators will also need to configure a staff's leadership status; either the staff is a staff or is a project manager. Project managers have additional capabilities which will be discussed more in-depth in later subchapters.

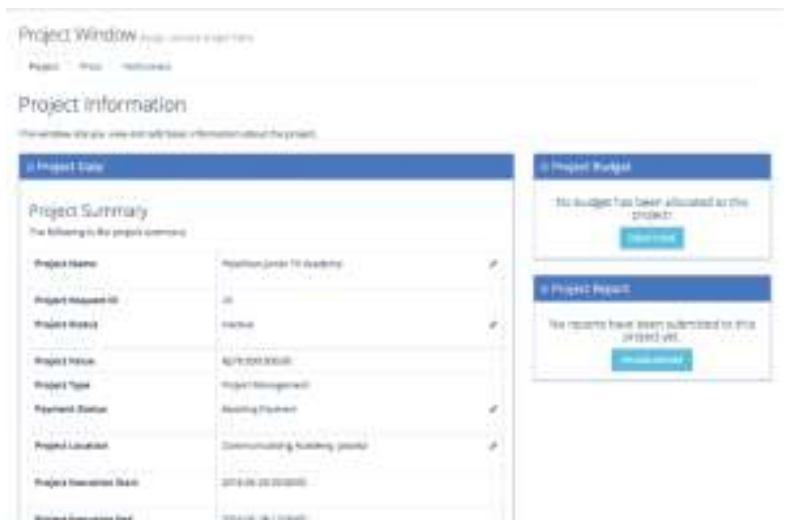

Figure 7 - Project information page

Aside from adding staffs, administrators also need to create budgets for the project to make sure that the project cost does not exceed its value. Budget items are categorized into configurable categories. Administrators can determine whether each category belongs to income or expenditure. Figure 8 shows the interface of project budget creation page.
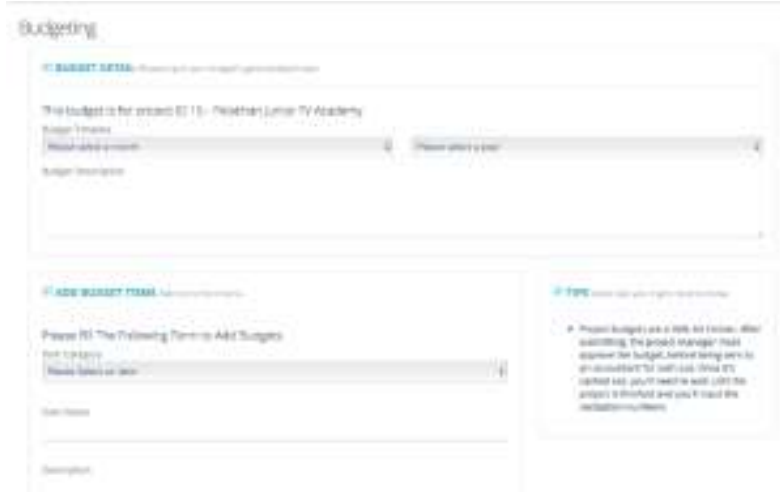

Figure 8 - Create new project budget

Once a project budget is created, it will need to be approved by the project's manager. Project managers are capable to either approve or disapprove the budget. If a manager chooses to do the latter, administrators will need to revise the budget. Project budgets must be approved. Otherwise, accountants will not be able to create realization plans, which, in reality, cash out the money required to pay for the project requirements.

\subsubsection{Managing The Budget}

Once a budget is successfully approved by a project manager, accountants can immediately create realization plans to either cash in or out the money. Cash in process is simpler than cash out and can be conducted by both project managers and accountants. Cash in process is also faster. It is immediately realized once it is created. Cash out process, however, is a little bit complicated. Only accountants can create cash out realization plans and realize them. To create a plan, accountants need to choose which item they want to realize, then pick the realization date. Realization plans cannot be realized before the designated realization date. Once realized, however, the application will not only generate a cash in/out document, but will also record the realization in the project budget, which will be reflected in the "Budgeting" section in project managers' project management app, which will be discussed in the next subchapter. Figure 9 shows the interface of realization plan page used by accountants.

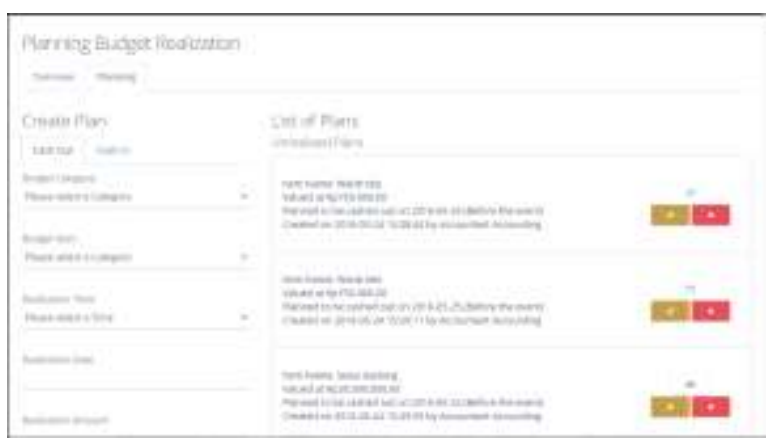

Figure 9 - Budget realization plan page

\subsubsection{Managing A Project}

This subchapter discusses the core feature of the application, where staffs can collaborate to deliver high-quality, successful projects. The project management interface used by staffs have four panes while project managers have an additional pane: Budgeting. The following is the explanation of each pane. 


\subsubsection{Project Overview}

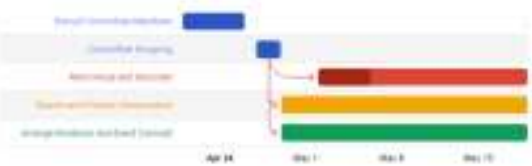

Figure 10 - Gantt chart generated in "Project Overview" pane

The Project Overview pane displays the essential information about the selected project such as project name, value, location, and execution date. In addition, it also displays the Gantt chart created by the project managers when available. The Gantt chart is powered by Google Charts and can be seen in Figure 10.

It is also possible to comment on the tasks within the Gantt chart. Users will need to switch from Gantt view to list view in order to view the task's details and post comments. This is due to the limitation of Google Charts. The author is not able to activate Google Chart's onSelect method in Google charts. Thus, the list view.

\subsubsection{Resources}

The "Resources" pane involves staffs. Project managers can group their staffs from this pane in addition to tagging them. Created groups are immediately registered in the database. On the other hand, project managers can also remove staffs from groups and delete their tags. Staffs, however, do not share this privilege. Staffs can only see their fellow colleagues and their groups and tags.

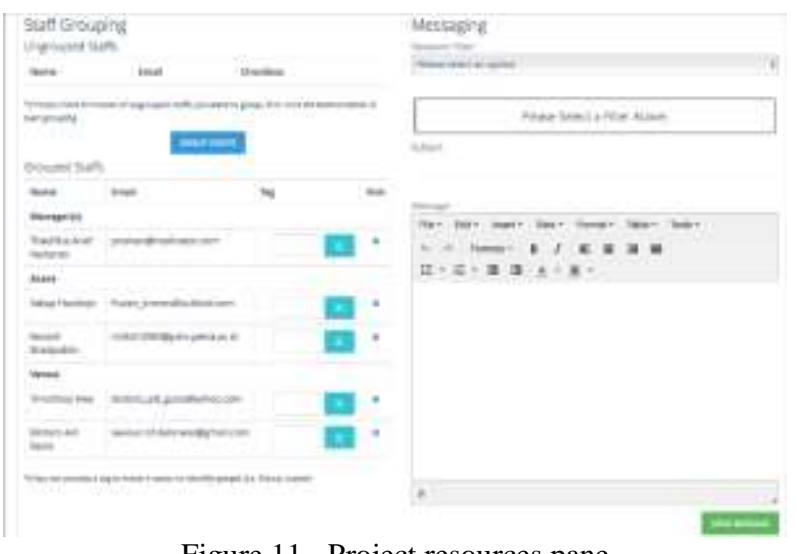

Figure 11 - Project resources pane

In addition to viewing, grouping, and tagging staffs, the Resources pane also allows staffs to send messages to other fellow staffs. Messages can also be broadcasted by choosing the appropriate filter then checking the appropriate checkboxes. There are four filters available:

- Tag, which means sending the message to only staffs with the selected $\operatorname{tag}(\mathrm{s})$.

- Group, which means sending the message to only selected group member(s).

- Individual, which means sending the message to only selected individual(s).

- Everyone, which means sending the message to every other staff.

Figure 12 shows the mailbox available to every project staff and a sample message.

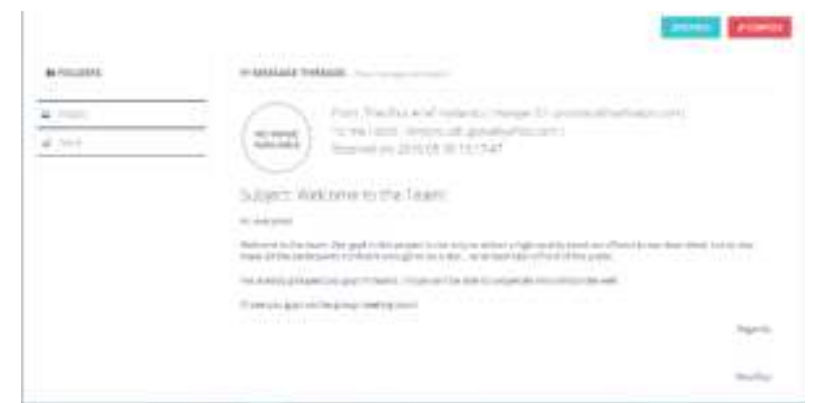

Figure 12 - Staff inbox and sample message

\subsubsection{Budgeting}
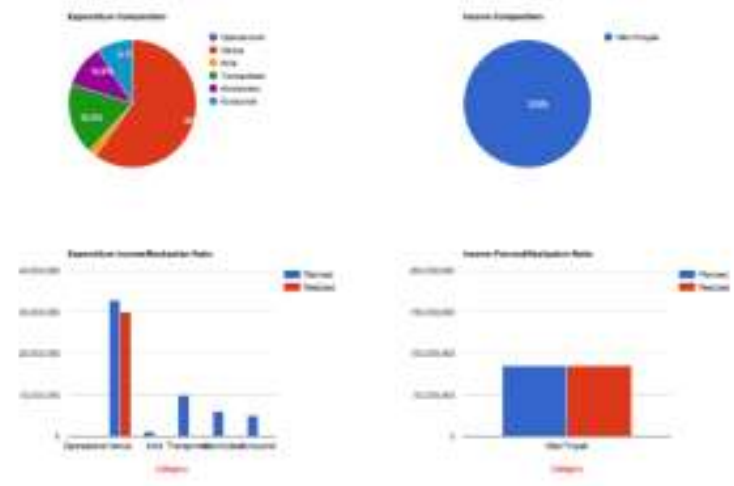

Figure 13 - Budgeting graphical information

The "Budgeting" pane allows project managers to view and control the usage of project budgets. Thus, this pane is only available to project managers. This pane consists of graphics informing the manager about the project's budget condition such as budget composition, planned/realization ratio as seen in Figure 13 in addition to budget information and list of budget documents. Project managers can also conduct a cashin from this pane.

\subsubsection{Gantt/Tasks}

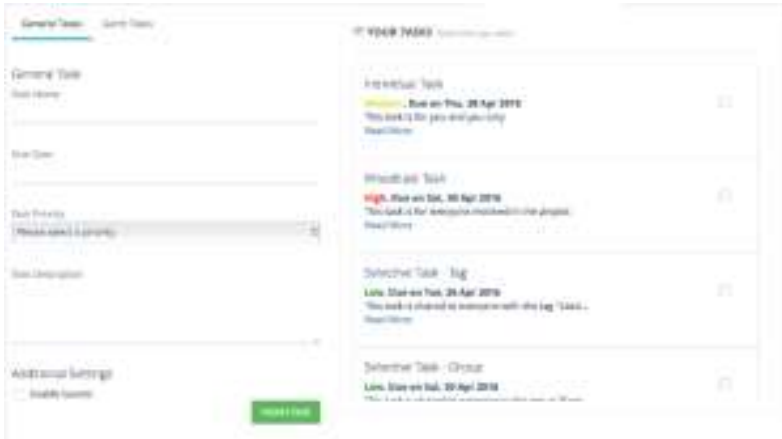

Figure 14 - Gantt/Task Pane

The "Gantt/Tasks" pane allows staffs to create tasks and project managers to create tasks which will be displayed in the Gantt chart. In addition to creating tasks for themselves, staffs can also share their tasks to other staffs. Shared tasks will be displayed on corresponding staffs' tasks pane. As for tasks displayed in Gantt chart, project managers can also task a certain group in the task. Please be noted, however, that a group must be created first before project managers can assign groups to the Gantt task. Figure 14 features the interface of Gantt/Task pane. 


\subsubsection{Documents}

Project Descument

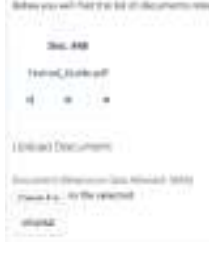

Figure 15 - Documents pane

In "Documents" pane, as seen in Figure 15, staffs are allowed to upload and share documents related to the project. Shared documents will be displayed in the guests' Documents pane and the guests will be able to view them. Documents shared in one project will not be displayed in other projects. In addition to uploading and sharing documents, staffs are also allowed to delete and view the documents. Viewing the document will open a new tab that will display the document and allow users to comment on it. However, the viewer will only be able to open PDF files. As for other file types, the user will be allowed to download the document. Document deletion is only available to document owners. Figure 16 shows the document viewer page.

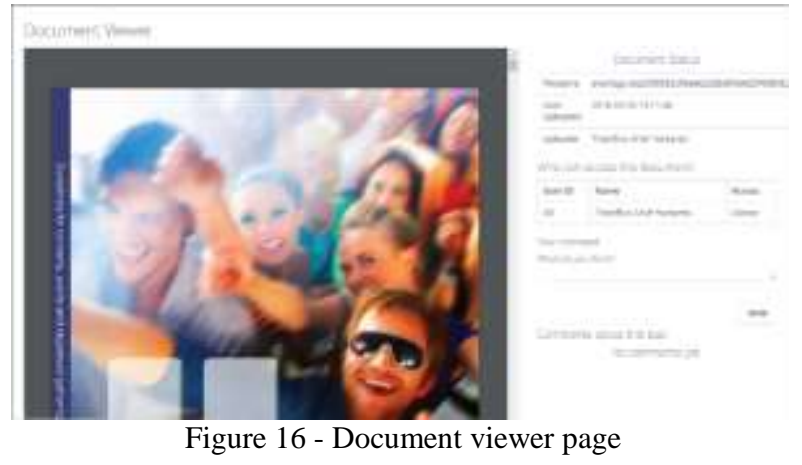

\section{CONCLUSION}

Based on the results of application implementation, the author has concluded the following:
- The application is able to take project requests and respond to it, assigning staffs and creating budgets as well as managing them.

- The application is able to create budget realization plans and integrate their realization into the budget project to be viewed by project managers.

- Staffs are able to view their project schedules via Gantt chart, giving themselves and their colleagues tasks and comment on them, communicate via messages, and uploading documents as well as sharing, viewing, and commenting on them. All of those are done within the application.

- $80 \%$ survey respondents argued that the overall application is good while the remaining $20 \%$ respondents argued that the overall application is very good. From the survey results, it can be concluded that the application has met the requirements set by $\mathrm{ABC}$ company.

\section{REFERENCES}

[1] Kemp, S. (2006). Project Management Made Easy. California: Entrepreneur Press.

[2] What is PHP?. Retrieved May 2, 2015. http://php.net/manual/en/intro-whatis.php

[3] Nixon, R. (2014). Learning PHP, MySQL, Javascript, CSS \& HTML5 (3rd ed). California: O'Reilly Media.

[4] Qureshi, M. \& Sabir, F. 2013. A Comparison Model View Controller and Model View Presenter. Sci.Int.(Lahore), 25(1):7-9.

[5] Kalelkar, M., Churi, P., Kalelkar, D. 2014. Implementation of Model-View-Controller Artchitecture Pattern for Business Intelligence Architecture. International Journal of Computer Applications, 102(12):16-21.

[6] Data Flow Diagram (DFD)s: An Agile Introduction. Retrieved May 29, 2016 http://www.agilemodeling.com/artifacts/dataFlowDiagra m.htm 